\title{
The association between cannabis use, mental illness, and suicidal behavior: what is the role of hopelessness?
}

\section{Gianluca Serafini ${ }^{1 *}$, Maurizio Pompili' , Marco Innamorati ${ }^{1}$, Elizabeth C. Temple ${ }^{2}$, Mario Amore ${ }^{3}$, Stefan Borgwardt ${ }^{4}$ and Paolo Girardi ${ }^{1}$}

\author{
1 Department of Neurosciences, Mental Health, and Sensory Organs, Sant'Andrea Hospital, Sapienza University of Rome, Rome, Italy \\ 2 School of Health Sciences, University of Ballarat, Ballarat, VIC, Australia \\ ${ }^{3}$ Department of Neuroscience, Rehabilitation, Ophthalmology, Genetics, Maternal and Child Health, Section of Psychiatry, University of Genova, Genova, Italy \\ 4 Department of Psychiatry, University of Basel, Basel, Switzerland \\ ${ }^{*}$ Correspondence: gianluca.serafini@uniroma1.it
}

Edited by:

Rhonda Frances Brown, The Australian National University, Australia

Keywords: cannabis use, major affective disorders, suicidal behavior, hopelessness, adolescence

\section{INTRODUCTION: THE COMPLEXITY OF CANNABIS MISUSE}

Cannabis is one of the most common illegal psychoactive substance used in European countries, in particular among adolescents and young adults (1). It has been estimated that almost $55 \%$ of adolescents aged 15-19 years have used cannabis at least once in their lifetime (2), while past year use is reported by approximately $30 \%$ of $15-17$ year olds and over $47 \%$ of those aged 18-19 years (3).

Cannabis use has been associated with several adverse life outcomes including unemployment, legal problems, dependence, early school leaving, increased risk of developing both psychotic and affective disorders $(3,4)$ together with brain structural and functional abnormalities $(5,6)$. An association between cannabis use, psychiatric disorders and suicidal behavior has also frequently been reported, although the exact nature of this link is still poorly understood (4).

Globally, suicide is one of the most common causes of death among young people aged $10-24$ years (6\% of deaths), exceeded only by motor vehicle accidents (10\%) (7). Over the last decade suicidal behavior has increased among adolescents and young adults, there has also been a trend toward the earlier initiation of cannabis use (8). This has led researchers to investigate the associations between the two factors to determine if cannabis use may be considered a factor that can trigger suicidal behavior.

Evidence indicates that cannabis use is significantly associated with both attempted and completed suicides among healthy youths (9) and both twin studies (10) and case-control comparisons (11) have shown the increased risk of suicide ideation/ attempts in those who use cannabis. Moreover, a longitudinal study found that frequent cannabis use (at least several times a week) predicted later suicidal ideation in susceptible males but not females (12). The earlier that this intense use first occurred and the higher the frequency of cannabis use, faster the susceptible individuals experienced suicidal thoughts.

Frequent and early cannabis use has also been associated with impaired mental wellbeing among young individuals (13, 14), and the risk of developing psychiatric conditions such as psychosis (15) and major affective disorders (16). Specifically, evidence suggests that cannabis use may exacerbate pre-existing conditions such as bipolar disorder, and predict negative outcomes and psychosocial impairment $(17,18)$. According to longitudinal studies, the high and frequent use of cannabis is also associated with longer recovery times for affective conditions, more hospitalizations, poorer compliance with treatment, increased aggression, and poorer response to treatment in patients with bipolar disorder type I and II $(12,17)$.

Nevertheless, it is important to note that many of the studies investigating associations between cannabis use and psychiatric conditions are cross-sectional in nature and cannot establish a causal relationship between the two phenomena (19). Further, several studies $(20,21)$ suggest a bidirectional relationship, as cannabis use variables do not solely explain the psychiatric outcomes observed nor do pre-existing psychiatric conditions fully explain the increased use of cannabis. Some researchers (22) have suggested that individuals with high levels of anxiety sensitivity or hopelessness may be more sensitive to the negative reinforcement processes of substance use (i.e., the ability of substances to modulate negative affective states) than non-affected individuals; however, some individuals experiencing the onset of mania or depression are not more likely to report increased cannabis use than those not experiencing these disorders (23, 24). In addition, other authors (25) have questioned the hypothesis that individuals may use cannabis to self-medicate psychotic or depressive symptoms.

In summary, cannabis use may be considered only as a risk factor, and possibly one of a great many that may predict the onset or exacerbation of affective disorders and suicidal behavior (26). Thus, whether cannabis use can trigger psychiatric disorders or only precipitate or exacerbate psychiatric conditions in vulnerable individuals, is still poorly understood.

\section{AFFECTIVE SYMPTOMS AND HOPELESSNESS: A POSSIBLE MEDIATING FACTOR?}

Depression, and in particular hopelessness, are widely recognized as strong predictors of suicidal behavior (15,27-29).Specifically, hopelessness has been shown to predict completed suicides among psychiatric patients after 10-20 years of follow-up (30, 31 ), and it is significantly associated with both adolescent self-harm and completed suicides (32).

Studies have also reported that hopelessness may be a risk factor of substance use suggesting that the presence of hopelessness could be considered a predictor of substance misuse $(33,34)$. With regard to cannabis use, Malmberg et al. (22) found that adolescents 
with high levels of hopelessness were more likely to have ever smoked cannabis when compared to adolescents with lower levels. The authors also suggested that increased levels of hopelessness were usually associated with earlier initiation of cannabis use. As such, it is possible that young adolescents experiencing hopelessness are more likely to use cannabis as a strategy to cope with their negative thoughts and feelings (35).

Informed by such research evidence, we suggest that the presence of hopelessness should be considered as a specific risk factor of negative outcome and suicidal behavior among depressed individuals with a history of early cannabis use. Thus in this review, we propose a theoretical model that addresses this issue (see Figure 1 for more details). This view is consistent with the hypothesis that early cannabis use may represent a relevant risk factor that can trigger or exacerbate suicidal behavior in vulnerable adolescents and young adults, with high hopelessness levels. In addition, vulnerable individuals may show hopelessness (36) and risk factors such as dysthymic temperamental traits $(37,38)$, dysthymia associated with periventricular white matter abnormalities (39), possibly the S-allele of the serotonin transporter gene polymorphism (5-HTTLPR) (40), sleep disturbances (e.g., insomnia) (41), abnormal pro-inflammatory cytokines levels (42), and/or comorbid symptom development (43). We highly recommend that the complex interaction between these variables is more closely investigated in adolescents at risk, in order to understand the possible emergence of depression and suicide.

However, studies including those informing the development of this model, should be considered in the light of significant shortcomings. Many of the studies were conducted using cross-sectional designs or included retrospective evaluations of lifetime behavior while attempting to predict long-term outcome variables or making reliable causal inferences. In addition, these studies adopted different measurements and outcome variables or they assessed patients at different time points (for more details see a complete list of limitations within Table 1 in Serafini et al. (15)). Further, not all studies included specific follow-up periods and only some of them were able to distinguish between suicide attempts and completions. Furthermore, the use of heterogeneous samples did not permit some researchers to determine a clear association between the onset of psychiatric conditions, suicidal behavior and the age of first cannabis use. Regarding retrospective studies, the absence

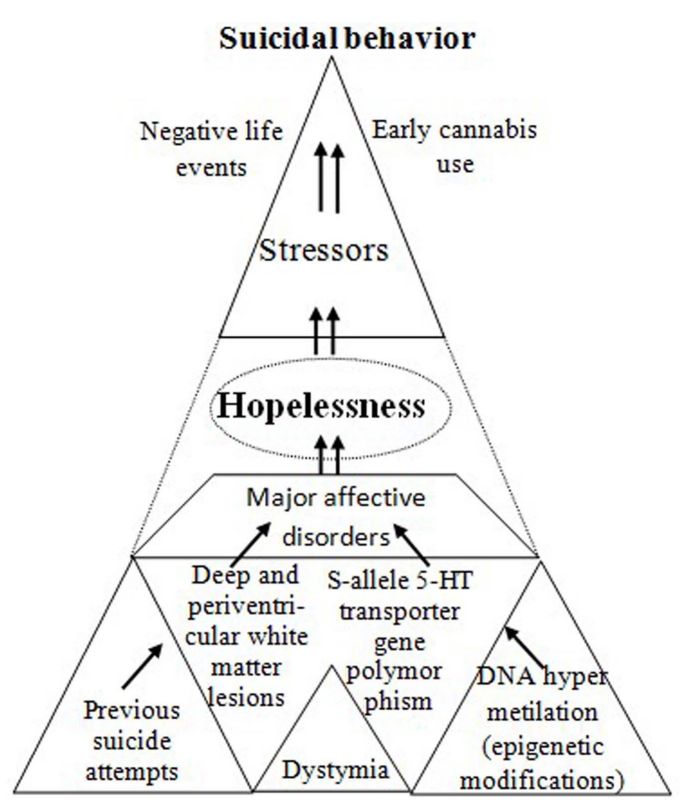

Modified by Serafini et al. (15)

FIGURE 1 |The complex interaction between risk factors involved in the emergence of suicidal behavior: the mediating effect of hopelessness.

of any strategies to ensure both inter-rater reliability and validity of the data also indicates that careful consideration must be given to the study results. Finally, the patients did not receive psychiatric assessments using structured psychometric instruments in all studies.

\section{IMPLICATIONS FOR PREVENTION}

Psychological distress and social decline need to be carefully investigated in young adolescents in order to provide appropriate ongoing management (44). Youth suicide prevention programs aimed at identifying risk behavior and the subgroups of individuals at high suicidal risk are absolutely necessary in clinical practice. Based on the current literature, such vulnerable subgroups of individuals include those who used cannabis early during adolescence (22), those who currently experience hopelessness (15), and those at high clinical risk of psychiatric conditions (45-47). Furthermore, vulnerable individuals usually present with additional risk factors that may severely influence their childhood development [e.g., a poor performance on tasks assessing sustained attention, impulse control and executive functioning (48)], presumably affecting both their suicide risk as well as early use of cannabis $(12,22,44$, 49-51) (for more details see Table 1).

Early warning signs of emerging psychiatric conditions such as behavioral, emotional, and cognitive changes, should be quickly recognized by clinicians by performing a multi-dimensional assessment of the patients (52). In addition, we recommend the careful assessment of hopelessness since it has been demonstrated to significantly increase the accuracy of suicide risk assessment by allowing the collection of reliable information about suicide risk even several years after the initial assessment (53). We also suggest that clinicians assess the current and past use of cannabis in their patients, including a determination of the age of initial use.

According to the affective model of prevention, young adolescents begin to use cannabis because they have poor selfesteem, poor self-control, and poor decision-making skills (35). In this context, youths may also experience negative expectations about their self and their future related to depression or pervasive feelings of loneliness (54). Prevention programs 
Table 1 | Risk factors for suicide risk and early cannabis use in adolescents.

\section{Socio-demographic}

and social factors

Individual factors
Death/loss of a parent or close friend

Social events including humiliation, loss, defeat, or threat

Interpersonal problems such as romantic difficulties

Poor social support

Financial or employment problems

Availability of weapons

Occasional failure at school or in society

Parental and family factors

Family history of suicide or suicide attempts

Family history of violence and aggression

Parental substance abuse and/or antisocial behavior

Parental separation or divorce

An argument with a parent

Disorganized family environment

History of physical/sexual abuse as a child or childhood maltreatment

Psychiatric disorders such as affective disorders and psychosis

Sleep disturbances such as insomnia

Antisocial and conduct problems

Loneliness

Impulsivity and poor self-control

Hopelessness

Neuroticism

Victimization

History of suicide attempts

Impairments in decisional competence and decision-making skills

Aggressive threats/fantasies

Dysthymic temperamental traits

Sources: van Ours et al. (12), Malmberg et al. (22), Beautrais et al. (49), Bridge et al. (50), Berger et al. (44), and Reinherz et al. (51).

aimed at helping young adolescents to clarify their subjective states, improve their decision-making abilities and enhance their self-esteem are available, thus potentially preventing the onset of hopelessness and subsequent suicidal ideation $(55,56)$. Young adolescents are expected to perceive the information provided in these programs as credible, otherwise they will not be likely to modify their behaviors (57). These prevention programs should be conducted during early adolescence and specifically focused on addressing hopelessness, although it is currently unclear whether the benefits may vary for different subgroups of adolescents (e.g., younger or older individuals) (57).

Evidence also suggests that school-based programs are very effective in preventing and/or reducing the use of cannabis among young adolescents, especially if they are able to provide active motivational strategies that inform adolescents about the prejudices against using psychoactive medications (55-57). For example, typical strategies may include actively explaining how to implement non-use behavior, such as coping skills for prodrug pressures and negative affective states, helping youths to understand that most people do not use cannabis, as well as increasing their awareness of the consequences of cannabis use and benefits related to non-use (57). In particular, research has demonstrated the efficacy of social-influence programs that use interactive (not didactic) sessions, and those that encourage active participation in small groups $(55,56)$.

In summary, clinicians need to be aware of the importance of preventive programs that are directed at preventing/treating modifiable factors such as adolescent hopelessness and/or delaying early cannabis use in specific subgroups of adolescents who experience major affective disorders.

\section{CONCLUSION}

Suicide, cannabis use, and psychiatric conditions (e.g., depression) are likely to be underpinned by similar complex factors.
Of particular interest for clinicians is the identification of individuals at risk of suicide who show early (i.e., prodromal) affective symptoms such as hopelessness. Suicide prevention programs may provide additional benefits if they focus on delaying or reducing adolescent cannabis use as well as responding to early signs of depression and hopelessness, which are widely recognized as important risk factors for suicide (58).

\section{REFERENCES}

1. EMCCDA. The State of the Drug Problems in Europe. Lisboa: EMCDDA (2006).

2. Hall W, Degenhardt L. Adverse health effects of nonmedical cannabis use. Lancet (2009) 374:1383-91. doi: 10.1016/S0140-6736(09)61037-0

3. Adlaf EM, Begin P, Sawka E. Canadian Addiction Survey: A National Survey of Canadians' Use of Alcohol and Other Drugs: Prevalence of Use and Related Harms: Detailed Report. Ottawa, ON: Canadian Centre on Substance Abuse (2005).

4. Moore THM, Zammit S, Lingford-Hughes A. Cannabis use and risk of psychotic or affective mental health outcomes: a systematic review. Lancet (2007) 370:319-28. doi: 10.1016/S0140-6736(07)61162-3

5. Rapp C, Bugra H, Riecher-Rössler A, Tamagni C, Borgwardt S. Effects of cannabis use on human brain structure in psychosis: a systematic review combining in vivo structural neuroimaging and post mortem studies. Curr Pharm Des (2012) 18:5070-80. doi: 10.2174/138161212802884861

6. Martín-Santos R, Fagundo AB, Crippa JA, Atakan $Z$, Bhattacharyya S, Allen P, et al. Neuroimaging in cannabis use: a systematic review of the literature. Psychol Med (2010) 40:383-98. doi: 10.1017/ S0033291709990729

7. Patton GC, Coffey C, Sawyer SM, Viner RM, Haller KM, Vos T, et al. Global patterns of mortality in young people: a systematic review of the literature. Lancet (2009) 374:881-92. doi: 10.1016/ S0140-6736(09)60741-8

8. Maharajh HD, Konings M. Cannabis and suicidal behaviour among adolescents: a pilot study from Trinidad. ScientificWorldJournal (2005) 5:576-85. doi: 10.1100/tsw.2005.79

9. Price C, Hemmingsson T, Lewis G, Zammit S, Allebeck P. Cannabis and suicide: longitudinal study. Br J Psychiatry (2009) 195:492-7. doi: 10.1192/bjp. bp.109.065227

10. Lynskey MT, Glowinski AL, Todorov AA, Bucholz KK, Madden PA, Nelson EC, et al. Major depressive disorder, suicidal ideation, and suicide attempt in twins discordant for cannabis dependence and early-onset cannabis use. Arch Gen Psychiatry (2004) 61:1026-32. doi: 10.1001/archpsyc.61.10.1026

11. BeautraisAL,JoycePR,MulderRT.Cannabisabuseand serious suicide attempts. Addiction (1999) 94:115564. doi: 10.1046/j.1360-0443.1999.94811555.x

12. van Ours JC, Williams J, Fergusson D, Horwood LJ. Cannabis use and suicidal ideation. J Health Econ (2013) 32:524-37. doi: 10.1016/j. jhealeco.2013.02.002

13. van Ours JC, Williams J. Cannabis use and mental health problems. J Appl Econ (2011) 26:1137-56. doi: 10.1002/jae.1182 
14. Henquet C, Krabbendam L, de Graaf R, ten Have $\mathrm{M}$, van Os J. Cannabis use and the expression of mania in the general population. J Affect Disord (2006) 95:103-10. doi: 10.1016/j.jad.2006.05.002

15. SerafiniG,Pompili M, Innamorati M, Rihmer Z, Sher L, Girardi P. Can cannabis increase the suicide risk in psychosis? A critical review. Curr Pharm Des (2012) 18:5165-87. doi: 10.2174/138161212802884663

16. van Ours JC, Williams J. The effects of cannabis use on physical and mental health. J Health Econ (2012) 31:564-77. doi: 10.1016/j.jhealeco.2012.04.003

17. Winter-van Rossum I, Boomsma MM, Tenback DE, Reed C, van Os J. [The influence of cannabis on the course of bipolar disorder: a longitudinal analysis]. Tijdschr Psychiatr (2010) 52:287-98.

18. Cerullo MA, Strakowski SM. The prevalence and significance of substance use disorders in bipolar type I and II disorder. Subst Abuse Treat Prev Policy (2007) 2:29. doi: 10.1186/1747-597X-2-29

19. Marshall M, Rathbone J. Early intervention for psychosis. Cochrane Database Syst Rev (2011) 6:CD004718.

20. Pacek LR, Martins SS, Crum RM. The bidirectional relationships between alcohol, cannabis, co-occurring alcohol and cannabis use disorders with major depressive disorder: results from a national sample. J Affect Disord (2013) 148:188-95. doi: 10.1016/j. jad.2012.11.059

21. Foti DJ, Kotov R, Guey LT, Bromet EJ. Cannabis use and the course of schizophrenia: 10-year follow-up after first hospitalization. Am J Psychiatry (2010) 167:987-93. doi: 10.1176/appi.ajp.2010.09020189

22. Malmberg M, Overbeek G, Monshouwer K, Lammers J, Vollebergh WA, Engels RC. Substance use risk profiles and associations with early substance use in adolescence. J Behav Med (2010) 33:474-85. doi: 10.1007/s10865-010-9278-4

23. Sanches RF, Marques JM. Cannabis and mood. Rev Bras Psiquiatr (2010) 32:173-80. doi: 10.1590/ S1516-44462010000200014

24. Calabria B, Degenhardt L, Hall W, Lynskey M. Does cannabis use increase the risk of death? Systematic review of epidemiological evidence on adverse effects of cannabis use. Drug Alcohol Rev (2010) 29:318-30. doi: 10.1111/j.1465-3362.2009.00149.x

25. Rey JM, Martin A, Krabman P. Is the party over? Cannabis and juvenile psychiatric disorder: the past 10 years. J Am Acad Child Adolesc Psychiatry (2004) 43:1194-205. doi: 10.1097/01. chi.0000135623.12843.60

26. Raphael B, Wooding S, Stevens G, Connor J. Comorbidity: cannabis and complexity. J Psychiatr Pract (2005) 11:161-76. doi: 10.1097/00131746-200505000-00004

27. Pompili M, Serafini G, Innamorati M, Biondi M, Siracusano A, Di Giannantonio M, et al. Substance abuse and suicide risk among adolescents. Eur Arch Psychiatry Clin Neurosci (2012) 262:469-85. doi: 10.1007/s00406-012-0292-0

28. Pompili M, Innamorati M, Rihmer Z, Gonda X, Serafini G, Akiskal H, et al. Cyclothymic-depressiveanxious temperament pattern is related to suicide risk in 346 patients with major mood disorders. J Affect Disord (2012) 136:405-11. doi: 10.1016/j. jad.2011.11.011

29. Pompili M, Serafini G, Innamorati M, Lester D, Shrivastava A, Girardi P, et al. Suicide risk in first episode psychosis: a selective review of the current literature. Schizophr Res (2011) 129:1-11. doi: 10.1016/j.schres.2011.03.008

30. Beck AT, Brown G, Steer RA. Prediction of eventual suicide in psychiatric inpatients by clinical ratings of hopelessness. JConsult Clin Psychol (1989) 57:309_ 10. doi: 10.1037/0022-006X.57.2.309

31. Brown GK, Beck AT, Steer RA, Grisham JR. Risk factors for suicide in psychiatric outpatients. A 20-year prospective study. J Consult Clin Psycho (2000) 68:371-7. doi: 10.1037/0022-006X.68.3.371

32. O'Connor RC, Fraser L, Whyte M, MacHale S, Masterton G. A comparison of specific positive future expectancies and global hopelessness as predictors of suicidal ideation in a prospective study of repeat self-harmers. J Affect Disord (2008) 110:207-14. doi: 10.1016/j.jad.2008.01.008

33. Kuo WH, Gallo JJ, Eaton WW. Hopelessness, depression, substance disorder, and suicidality - a 13-year community-based study. Soc Psychiatry Psychiatr Epidemiol (2004) 39:497-501. doi: 10.1007/ s00127-004-0775-z

34. Jaffee WB, D'Zurilla TJ. Personality, problem solving, and adolescent substance use. Behav Ther (2009) 40:93-101. doi: 10.1016/j.beth.2008.03.001

35. Hyman SM, Sinha R. Stress-related factors in cannabis use and misuse: implications for prevention and treatment. JSubst Abuse Treat (2009) 36:400-13. doi: 10.1016/j.jsat.2008.08.005

36. Iliceto P, Pompili M, Girardi P, Lester D, Vincenti C, Rihmer Z, et al. Hopelessness, temperament, and health perception in heroin addicts. J Addict Dis (2010) 29:352-8. doi: 10.1080/10550887.2010.489448

37. Pompili M, Rihmer Z, Akiskal H, Amore M, Gonda $\mathrm{X}$, Innamorati $\mathrm{M}$, et al. Temperaments mediate suicide risk and psychopathology among patients with bipolar disorders. Compr Psychiatry (2012) 53:280-5. doi: 10.1016/j.comppsych.2011.04.004

38. Rihmer A, Rozsa S, Rihmer Z, Gonda X, Akiskal KK, Akiskal HS. Affective temperaments, as measured by TEMPS-A, among nonviolent suicide attempters. J Affect Disord (2009) 116:18-22. doi: 10.1016/j. jad.2008.10.024

39. Serafini G, Pompili M, Innamorati M, Fusar-Poli P, Akiskal HS, Rihmer Z, et al. Affective temperamental profiles are associated with white matter hyperintensity and suicidal risk in patients with mood disorders. J Affect Disord (2011) 129:47-55. doi: 10.1016/j.jad.2010.07.020

40. Gonda X, Rihmer Z, Zsombok T, Bagdy G, Akiskal KK, Akiskal HS. The 5HTTLPR polymorphism of the serotonin transporter gene is associated with affective temperaments as measured by TEMPS-A. J Affect Disord (2006) 91:125-31. doi: 10.1016/j. jad.2005.12.048

41. Roane BM, Taylor DJ. Adolescent insomnia as a risk factor for early adult depression and substance abuse. Sleep (2008) 31:1351-6.

42. Serafini G, Pompili M, Elena Seretti M, Stefani H, Palermo M, Coryell W, et al. The role of inflammatory cytokines in suicidal behavior: a systematic review. Eur Neuropsychopharmacol(2013) (in press). doi: 10.1016/j.euroneuro.2013.06.002

43. McManama O, Brien KH, Berzin SC. Examining the impact of psychiatric diagnosis and comorbidity on the medical lethality of adolescent suicide attempts. Suicide Life Threat Behav (2012) 42:437-44. doi: 10.1111/j.1943-278X.2012.00102.x
44. Berger G, Fraser R, Carbone S, McGorry P. Emerging psychosis in young people - Part 1 - key issues for detection and assessment. Aust Fam Physician (2006) 35:315-21.

45. Atakan Z, Bhattacharyya S, Allen P, Martín-Santos R, Crippa JA, Borgwardt SJ, et al. Cannabis affects people differently: inter-subject variation in the psychotogenic effects of $\Delta 9$-tetrahydrocannabinol: a functional magnetic resonance imaging study with healthy volunteers. Psychol Med (2012) 43(6):125567. doi: 10.1017/S0033291712001924

46. Denier N, Walter M, Bendfeldt K, Lang U, Borgwardt S. Resting state abnormalities in psychosis compared to acute cannabinoids and opioids challenges: a systematic review of functional imaging studies. Curr Pharm Des (2012) 18:5081-92. doi: $10.2174 / 138161212802884717$

47. Chistiakov DA, Kekelidze ZI, Chekhonin VP. Endophenotypes as a measure of suicidality. $J$ Appl Genet (2012) 53:389-413. doi: 10.1007/ s13353-012-0113-1

48. Fontes MA, Bolla KI, Cunha PJ, Almeida PP, Jungerman F, Laranjeira RR, et al. Cannabis use before age 15 and subsequent executive functioning. Br J Psychiatry (2011) 198:442-7. doi: 10.1192/ bjp.bp.110.077479

49. Beautrais A, Collings S, Ehrhardt P. Suicide Prevention: A Review of Evidence of Risk and Protective Factors, and Points of Effective Intervention. Wellington: Ministry of Health (2005).

50. Bridge J, Goldstein T, Brent D. Adolescent suicide and suicidal behavior. J Child Psychol Psychiatry (2006) 47:372-94. doi: 10.1111/j.1469-7610.2006.01615.x

51. Reinherz HZ, Paradis AD, Giaconia RM, Stashwick CK, Fitzmaurice G. Childhood and adolescent predictors of major depression in the transition to adulthood. Am J Psychiatry (2003) 160:2141-7. doi: 10.1176/appi.ajp.160.12.2141

52. Taliaferro LA, Borowsky IW. Perspective: physician education: a promising strategy to prevent adolescent suicide. Acad Med (2011) 86:342-7. doi: 10.1097/ACM.0b013e31820984ad

53. Beck AT, Weissman A, Lester DLT. The measurement of pessimism: the hopelessness scale. J Consult Clin Psychol (1974) 42:861-5. doi: 10.1037/ h0037562

54. Klonsky DE, Kotov R, Bakst S, Rabinowitz J, Bromet EJ. Hopelessness as a predictor of attempted suicide among first admission patients with psychosis: a 10-year cohort study. Suicide Life Threat Behav (2012) 42:1-10. doi: 10.1111/j.1943-278X.2011.00066.x

55. Tobler NS, Stratton HH. Effectiveness of schoolbased drug prevention programs: a meta-analysis of the research. J Prim Prev (1997) 18:71-128. doi: 10.1023/A:1024630205999

56. Tobler NS, Roona MR, Ochshorn P, Marshall DG, Streke AV, Stackpole KM. School-based adolescent drug prevention programs: 1998 metaanalysis. J Prim Prev (2000) 20:275-336. doi: 10.1023/A:1021362620740

57. Porath-Waller AJ, Beasley E, Beirness DJ. A metaanalytic review of school-based prevention for cannabis use. Health Educ Behav (2010) 37:709-23. doi: $10.1177 / 1090198110361315$

58. Wu P, Hoven CW, Liu X, Cohen P, Fuller CJ Shaffer D. Substance use, suicidal ideation and 
attempts in children and adolescents. Suicide Life Threat Behav (2004) 34:408-20. doi: 10.1521/ suli.34.4.408.53733

Received: 26 April 2013; accepted: 23 September 2013; published online: 11 October 2013.

Citation: Serafini G, Pompili M, Innamorati M, Temple EC, Amore M, Borgwardt S and Girardi P (2013) The association between cannabis use, mental illness, and suicidal behavior: what is the role of hopelessness? Front. Psychiatry 4:125. doi: 10.3389/fpsyt.2013.00125

This article was submitted to Addictive Disorders and Behavioral Dyscontrol, a section of the journal Frontiers in Psychiatry.

Copyright $(2013$ Serafini, Pompili, Innamorati, Temple, Amore, Borgwardt and Girardi. This is an open-access article distributed under the terms of the Creative Commons Attribution License (CC BY). The use, distribution or reproduction in other forums is permitted, provided the original author(s) or licensor are credited and that the original publication in this journal is cited, in accordance with accepted academic practice. No use, distribution or reproduction is permitted which does not comply with these terms. 